Успехи физ. мет. / Usp. Fiz. Met. 2015, т. 16, сc. 23-34 Оттиски доступны непосредственно от издателя Фотокопирование разрешено только в соответствии с лицензией (с) 2015 ИМФ (Институт металлофизики им. Г. В. Курдюмова НАН Украины)

Напечатано в Украине.

PACS numbers: 46.25.Hf, 62.20.fg, 64.70.kd, 65.40.De, 81.30.Kf, 81.40.Jj

\title{
Hysteresis Phenomena and Their Modelling in Martensitic Transformation Thermodynamics
}

\author{
O. A. Likhachev and Yu. M. Koval
}

G. V. Kurdyumov Institute for Metal Physics, N.A.S. of Ukraine, 36 Academician Vernadsky Blvd., UA-03680 Kyiv-142, Ukraine

In the present review paper, we show that a successful description of the irreversible evolution of macroscopic variables during the martensitic transformations caused by hysteresis is possible with using a special type of differential equations with the temperature-dependent coefficient depending only on the main hysteresis loop shape. These equations make it possible to predict the macroscopic volume fraction evolution for an arbitrary temperature change process including the partial subloops. For this aim, one should know only the information about the temperature behaviour for transformation paths representing the main hysteresis loop. The present model is practically applied and experimentally confirmed for martensitic transformation in $\mathrm{CuZnAl}$ alloy.

У даній оглядовій статті показано, що успішний опис незворотньої еволюції макроскопічних змінних, зумовленої гістерези в процесі мартенситних перетворень, є можливим при використанні диференційних рівнянь спеціяльного типу з температурозалежними коефіцієнтами, що визначаються виключно формою основної петлі гістерези. Ці рівняння дають можливість передбачати еволюцію макроскопічної частки мартенситу для довільного процесу зміни температури, включаючи часткові петлі мартенситного перетворення. Для цього потрібно знати лише їі температурну залежність для основної петлі гістерези. Зазначений модель практично застосовано та експериментально перевірено для випадку мартенситного перетворення у стопі CuZnAl.

В данной обзорной статье показано, что успешное описание необратимой эволюции макроскопических переменных, обусловленной гистерезисом в процессе мартенситных превращений, возможно путём использования дифференциальных уравнений специального типа с температурнозависимыми коэффициентами, которые определяются исключительно формой основной петли гистерезиса. Эти уравнения дают возможность предсказывать эволюцию макроскопической фракции мар- 
тенсита для произвольного процесса изменения температуры, включая частичные петли мартенситного превращения. Для этого необходимо знать лишь её поведение на основной петле гистерезиса. Указанная модель практически применена и экспериментально проверена для случая мартенситного превращения в сплаве $\mathrm{CuZnAl}$.

Key words: shape-memory alloys, martensitic transformation, hysteresis, thermoelastic equilibrium.

(Received January 12, 2015)

\section{INTRODUCTION}

Many unusual thermo-mechanical properties of shape-memory alloys are directly connected with martensitic type phase transitions in these systems. Because the martensitic transformations, as a rule, are the first order transitions, a special attention should be attracted to a hysteretic behaviour of shape-memory alloys. The most important characteristics of the temperature- or stress-induced martensitic transformation have been studied in detail in [1-5]. It has been shown that due to thermomechanical hysteresis in solids undergoing martensitic type of structure transformations the macroscopic strain and volume fraction of martensite are not a singlevalued function of stress and temperature, but they become functions of the process of their change. Therefore, the shape-memory alloys should be considered as systems having infinite number of state equations that represent the inelastic strain and volume fraction of martensite as functions of the external stress and temperature, correspondingly.

Some of the phenomenological approaches describing main thermomechanical properties of shape-memory alloys (SMA) connected with hysteresis were recently developed in [6-10, 14]. In particular, a special type of differential equations (DE) describing evolution of the inelastic macroscopic strain and volume fraction of martensite as functions of the temperature has been proposed in our recent papers $[11,12,19,20]$. Simplest applications of these equations to a strain evolution during the multiple temperature cycling in a small temperature interval have been also discussed [21,22].

During the last time, the models that are similar, but not identical, to that studied in [11-12] were analysed in [15-18].

These and some other problems associated with the irreversible processes caused by hysteresis will be discussed in the present paper. The main aim is to consider a possible application of these equations to the temperature-induced MT and to discuss new interpretation of DE method based on the transition probability concept. 


\section{SOME GENERAL ASPECTS}

At the macroscopic level, the martensitic transformation process can be represented by corresponding macroscopic variables. The investigation of their evolution gives the necessary information on the general peculiarities of martensitic transformation kinetics in solids under the external thermodynamical forces applied. As well known for the martensitic type phase transitions, the temperature and mechanical stress are the main external forces that can essentially influence the transformation process. In particular, direct as well as reverse transformation process can be induced in the material due to the corresponding temperature or stress change. The macroscopic state variables such as martensite volume fraction and macroscopic strain represent quantitatively the transformation result. As follows from different experimental studies, all these state variables are usually very complex multi-valued functions of the external driving forces. Strictly speaking, the state variables cannot be more considered as functions of current values of the stress or temperature, but instead, they become functions of the external driving forces change. Such behaviour is caused by the thermomechanical hysteresis of the materials undergoing first order diffusionless martensitic phase transition.

In particular, the volume fraction of martensitic phase can be considered as the most representative macroscopic state variable for the temperature-induced martensitic transformation occurring without any external stress applied. As follows from different studies, the transformation process can be represented by the main hysteresis loop describing martensite volume fraction change during the direct and reverse martensitic transformation on cooling and heating, respectively. Besides of the global transformation cycle, a set of subloops representing partially direct and reverse transformation processes are usually observed, as indicated in Fig. 1. A definite return point, where the cooling process is replaced by heating or vice versa, characterizes each partial subloop.

It should be also noted that each point inside the main loop represents one of the possible stationary two-phase states of the system. All these are the metastable ones, because no volume fraction change is usually observed if one stops the cooling or heating process at this point for any time. This also denotes that thermal fluctuations do not play any significant role in MT. As a result, transitions from one metastable state to another one are only possible on driving the system with any external thermodynamical force, such as a temperature or stress. Therefore, all the transformation paths in Fig. 1 represent continuous sequences of metastable states that the system can run on driving by the temperature change process. 

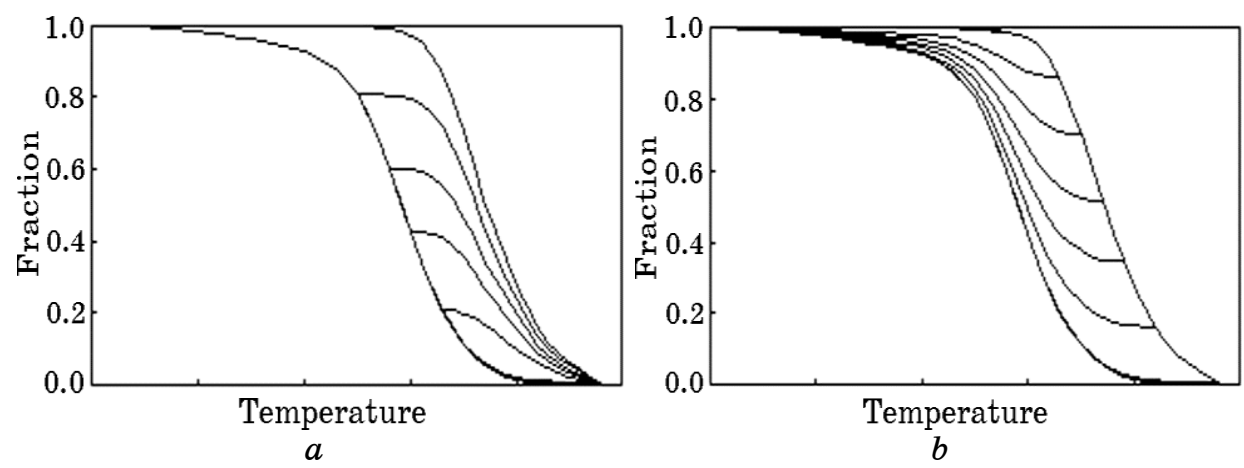

Fig. 1. A scheme of the typical martensite volume fraction hysteresis behaviour during the complete and partial martensitic transformation.

Definite efforts have been made by several authors to find the corresponding constitutive methods to describe the main peculiarities of MT-kinetics. In particular, Cory and McNichols [6] have developed the approximation scheme of MT based on an infinite set of state equations representing evidently families of partial transformation trajectories. Likhachev and Koval $[11,12,19,20]$ have proposed a special type differential equation describing evolution of the inelastic strain and volume fraction of martensite during the partial temperature-induced MT. Recently, Ivshin and Pence [17, 18] considered the differential model that is similar, but not identical, to that studied in $[11,12]$. The main distinguishes and similarity of these different models will be briefly discussed in the next sections of this report.

\section{DIFFERENTIAL REPRESENTATION OF THE PARTIAL MARTENSITIC TRANSFORMATION SUBLOOPS}

As follows from the results represented in Fig. 1, the temperature induced macroscopic volume fraction $\chi=\chi(T)$ of martensitic phase can be characterized by two branches of a global hysteresis loop $\chi=z_{-}(T)$ and $\chi=z_{+}(T)$ corresponding to cooling and heating processes, respectively. Additionally, a family of minor subloops representing partial martensitic transformation processes are also shown here. Therefore, the martensite volume fraction is always a definite function of the temperature change that can take the multiple values inside of the main hysteresis loop.

To describe the irreversible evolution of macroscopic variables caused by hysteresis including the minor subloops, the one possible way based on the differential equation method (DEM) has been proposed in our works $[11,12]$. Such a possibility follows immediately 
from the assumption that only a single path from each minor family in Fig. 1 can pass through a given point with coordinates $(\chi, T)$ inside of the main hysteresis loop. Therefore, only a single value of the first derivative $d \chi / d T$ for the cooling or heating family of paths may correspond to each point in the $(\chi, T)$ plane. Mathematically, this denotes that $d \chi / d T$ must be a single-valued function of $\chi$ and $T$ both for the cooling and heating processes. Accordingly, each thermodynamical path belonging to the cooling or heating family must satisfy the following type of differential equations:

$$
d \chi / d T=S_{ \pm}(\chi, T),
$$

where $S_{ \pm}(\chi, T)$ are single-valued functions of $(\chi, T)$ associated with the heating and cooling processes that are signed as $( \pm)$, respectively. It has also been found [12] that $S_{ \pm}(\chi, T)$ can be expressed as a linear function of $\chi$

$$
S_{ \pm}(\chi, T)=\alpha_{ \pm}(T) \chi+\beta_{ \pm}(T)
$$

with the temperature dependent coefficient $\alpha_{ \pm}(T)$ and $\beta_{ \pm}(T)$ depending only on the main hysteresis loop shape represented by $z_{ \pm}(T)$ functions:

$$
\alpha_{ \pm}(T)= \pm \frac{d z_{ \pm}}{d T} \frac{1}{z_{+}-z_{-}}, \beta_{ \pm}(T)=\mp \frac{d z_{ \pm}}{d T} \frac{z_{\mp}}{z_{+}-z_{-}} .
$$

Therefore, the differential equations for the basic heating and cooling path family are as follow:

$$
d \chi / d T= \pm \frac{d z_{ \pm}}{d T}\left(\frac{\chi-z_{\mp}}{z_{+}-z_{-}}\right) .
$$

These equations make it possible to predict the volume fraction evolution for any temperature change process. For this aim, in accordance with Eq. (4), one should know only the information about the temperature behaviour of $z_{ \pm}(T)$-paths representing the main hysteresis loop.

These equations can be also represented in the time-evolutionary form. Because of the time derivative of $\chi(T)$ is $\dot{\chi}=\dot{T}(d \chi / d T)$ and using Eqs. (1), (2), one can easily obtain the following equations:

$$
d \chi / d T=\alpha_{ \pm}(T) \chi+\beta_{ \pm}(T) .
$$

These ones can be considered as kinetic equations describing athermal type of martensitic transformation kinetics.

The experimental evidence of the linearity rules found in [12] 
from the investigation of shape-memory effect in $\mathrm{Ni}-\mathrm{Ti}$ alloy is shown in Figs. 2 and 3.

Figures 4 and 5 exhibit good quantitative agreement between the measured and calculated partial trajectories has been recently found

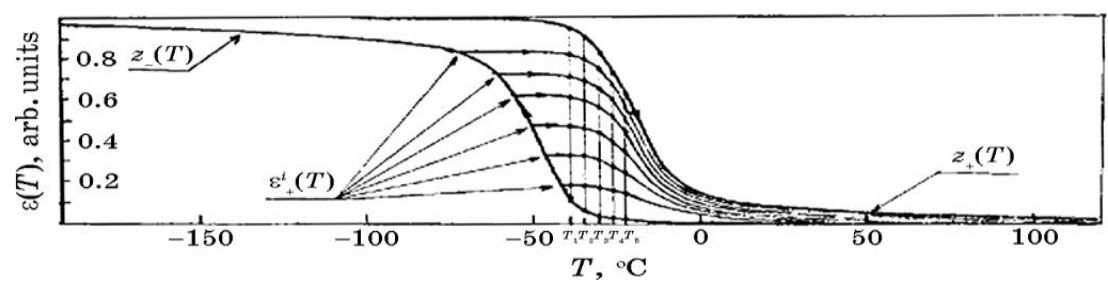

Fig. 2. Experimental data representing the main hysteresis loop $z_{ \pm}(T)$ and heating family of partial transformation paths $\varepsilon_{+}^{i}(T)$ for the $\mathrm{Ni}_{51} \mathrm{Ti}_{49}$ shape-memory alloy.

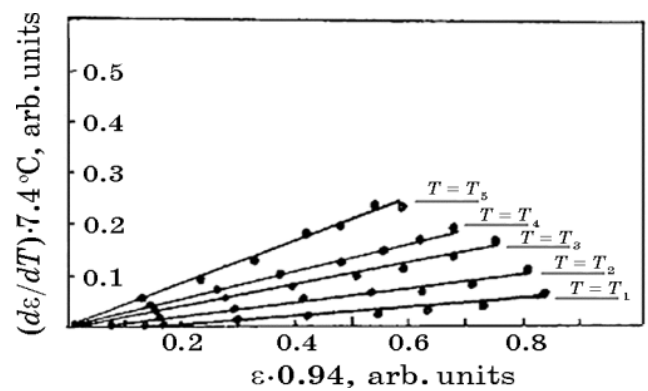

Fig. 3. The linearity rules between $d \varepsilon_{+} / d T$ and $\varepsilon_{+}$found for several temperatures $\left(T_{1}, T_{2}, T_{3}, T_{4}\right.$, and $\left.T_{5}\right)$ indicated in Fig. 2.

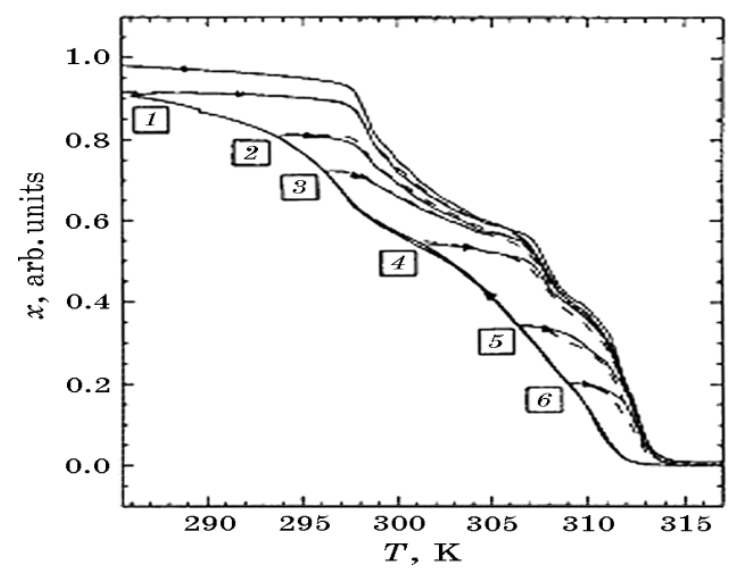

Fig. 4. Comparison of the hysteresis loop obtained experimentally (solid line) and those determined from the model (dashed line). 


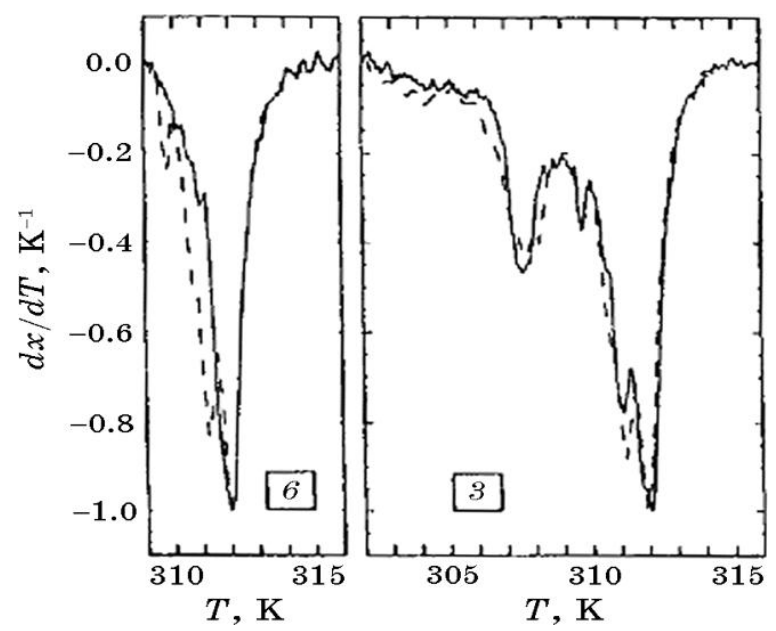

Fig. 5. Comparison between the slope of the actual heating partial cycling branches (solid line) and the slope determined from the model (dashed line). These two figures correspond to the 3 and 6 partial cycles in Fig. 2.
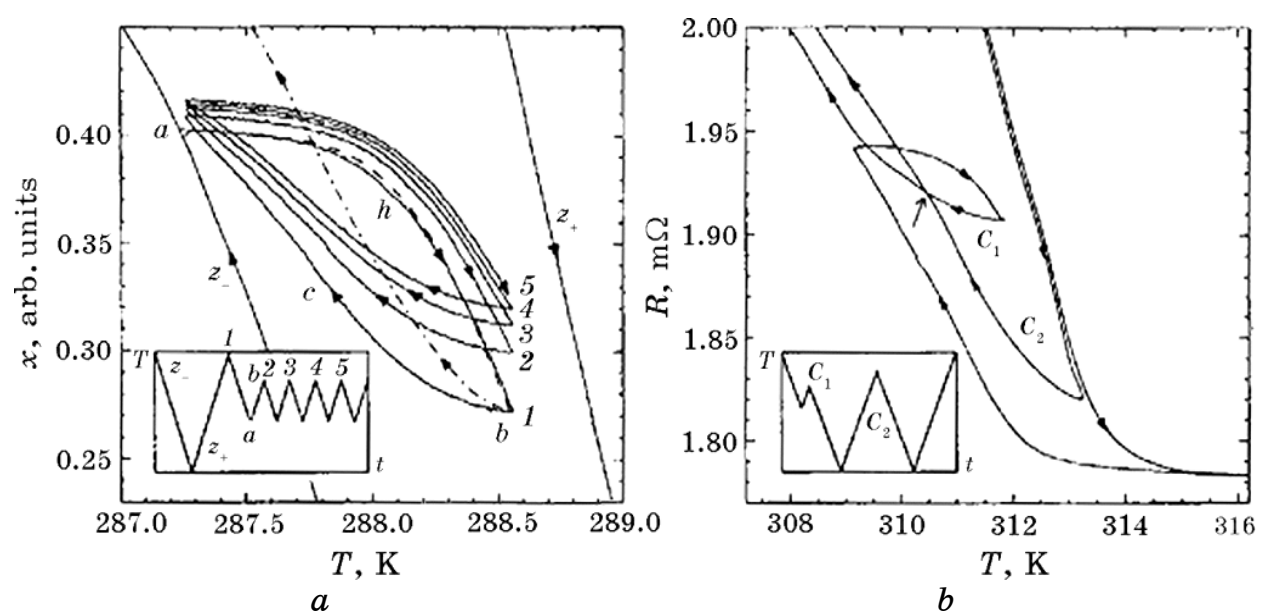

Fig. 6. High order subloops showing hysteretic behaviour of $\mathrm{CuZnAl}$ alloy during the multiple partial cycling.

in [24]. Examples of high order partial subloops are shown in Fig. 6.

\section{RELATIONSHIPS BETWEEN DIFFERENTIAL EQUATION METHOD AND OTHER HYSTERESIS MODELS}

Cory and McNichols in their original work [6] have developed the phenomenological scheme of MT thermomechanics including as 
stress and temperature hysteresis effects as well the evident analytic expression of the partial transformation trajectories. Although these authors have not used any differential representation of their equations for partial transformation trajectories, nevertheless, one can easily reduce these equations to the same differential form as Eqs. (1) and (2) in the preceding section (see Ref. [23]).

Consider for simplicity the temperature-induced MT without external stress applied, when the volume fraction $\chi(T)$ can be chosen as a unique representative macroscopic state variable displaying transformation process. According to CM-approach the differences between the current value of $\chi(T)$ and $z_{ \pm}(T)$-paths representing main hysteresis loop can be satisfactory expressed in the following exponential form:

$$
\chi(T)-z_{ \pm}(T)=a_{ \pm} \exp \{\mp T / \tau\} .
$$

Here, $\tau$ is the characteristic constant of the material that (following to $\mathrm{CM})$ can be chosen from the best fit to experiment; $( \pm$ ) denote the heating or cooling process, correspondingly; the different values of $a_{+}$-constants determine a set of possible partial trajectories for heating and cooling processes.

Taking $T$-derivative of these equations,

$$
d \chi / d T-d z_{ \pm} / d T=\mp \tau^{-1} a_{ \pm} \exp \{\mp T / \tau\},
$$

and replacing the exponential term by its expression following from Eq. (6), we easily find the differential equation for the partial trajectories in the framework of CM-approximation:

$$
d \chi / d T=\alpha_{ \pm}^{C M}(T) \chi+\beta_{ \pm}^{C M}(T)
$$

with temperature-dependent coefficients $\alpha_{ \pm}^{C M}(T)$ and $\beta_{ \pm}^{C M}(T)$ equal to:

$$
\alpha_{ \pm}^{C M}(T)=\mp \tau^{-1}, \beta_{ \pm}^{C M}(T)=d z_{ \pm} / d T \mp \tau^{-1} z_{ \pm} .
$$

Therefore, CM-approach is really reduced to a same type of differential equation that follows from DEM. Moreover, the expressions of $\alpha_{ \pm}^{C M}(T)$ and $\beta_{ \pm}^{C M}(T)$ found in framework of DEM will approach to $\alpha_{ \pm}^{C M}(T)$ and $\beta_{ \pm}^{C M}(T)$ values following from CM-approximation in the case when the temperature hysteresis value $\tau_{\mathrm{h}}$ becomes very small. This result follows immediately from Taylor's expansion of the evident relations between $z_{+}$and $z_{-}$functions, as $\tau_{\mathrm{h}} \rightarrow 0$ :

$$
z_{ \pm}(T)=z_{\mp}\left(T \mp \tau_{\mathrm{h}}\right) \approx z_{\mp}(T) \mp \tau_{\mathrm{h}}\left(d z_{\mp} / d T\right) .
$$

So, one can conclude that 
TABLE 1. Comparison of different models in respect to basic items of DEM.

\begin{tabular}{ccccc}
\hline Model & Item (I) & Item (II) & Item (III) & Item (IV) \\
\hline C-M & $\mathrm{Y}$ & $\mathrm{Y}$ & $\mathrm{N}$ & $\mathrm{Y}$ \\
$\mathrm{L}-\mathrm{K}$ & $\mathrm{Y}$ & $\mathrm{Y}$ & $\mathrm{Y}$ & $\mathrm{Y}$ \\
$\mathrm{I}-\mathrm{P}$ & $\mathrm{Y}$ & $\mathrm{Y}$ & $\mathrm{N}$ & $\mathrm{Y}$ \\
\hline
\end{tabular}

$$
\alpha_{ \pm}^{L K}(T) \rightarrow \mp \tau_{\mathrm{h}}^{-1}, \beta_{ \pm}^{L K}(T) \rightarrow d z_{\mp} / d T \mp \tau_{\mathrm{h}}^{-1} z_{ \pm} .
$$

Therefore, CM-approach can be considered as a small hysteresis limit of DEM. In particular, material constant $\tau$ can be chosen equal to a temperature hysteresis value $\tau_{\mathrm{h}}$.

Other differential model that is similar but not identical to the discussed above has been considered in [17, 18].

It should be also noted that the constitutive DEM equations could be easily derived from the general items presented below.

\section{Basic points of DEM:}

(i) uniqueness of thermodynamical trajectory $d \chi / d T=S_{ \pm}(\chi, T)$;

(ii) self-consistency requirement $S_{+}\left(z_{+}, T\right)=d z_{+} / d T$;

(iii) return point boundary conditions $S_{+}\left(z_{-}, T\right)=0$;

(iv) linearity rule $S_{ \pm}(\chi, T)=\alpha_{ \pm}(T) \chi+\beta_{ \pm}(T)^{+}$.

In respect to these points, the comparison of three models: (CM)-Cory \& McNichols (1985), (LK)-Likhachev \& Koval (1988, 1992), (IP)-Ivshyn \& Pence (1992) is represented in the Table 1.

It is also interesting that LK-model can be reduced to both others in two different limits:

$(\mathrm{CM}) \leftarrow$ small hysteresis limit $\leftarrow$ (LK) $\rightarrow$ wide hysteresis limit $\rightarrow$ (IP)

\section{TRANSITION PROBABILITY CONCEPT IN MARTENSITIC TRANSFORMATION KINETICS}

To understand better the nature of differential equation method, a very important physical interpretation based on the master kinetic equation concept will be considered in this section. As follows from this well known in physics general concept, the transformation kinetic equations describing reactions between two phases $a \leftrightarrow m$ (austenite $\leftrightarrow$ $\leftrightarrow$ martensite) can be represented in the following general form:

$$
\begin{aligned}
& \dot{\chi}_{m}=-W^{m \rightarrow a} \chi_{m}+W^{a \rightarrow m} \chi_{a}, \\
& \dot{\chi}_{a}=-W^{a \rightarrow m} \chi_{a}+W^{m \rightarrow a} \chi_{m} .
\end{aligned}
$$

These equations represent the temporal evolution of the martensitic 
( $m$ ) or austenitic (a) phase fraction due to the local $m \rightarrow a$ and $a \rightarrow m$ microscopic transformation processes with the corresponding transition probabilities: $W^{m \rightarrow a}$ and $W^{a \rightarrow m}$. Here, $\dot{\chi}_{m}$ and $\dot{\chi}_{a}$ denote the rates of $\chi_{m}$ and $\chi_{a}$ changes, respectively. The considered kinetic equations satisfy automatically the following conservation rule:

$$
\chi_{m}+\chi_{a}=\text { const } .
$$

Naturally, this time-independent constant must be equal 1 because, at the initial stage of transformation process, the system must contain the austenitic phase only, and $\chi_{m}=0, \chi_{a}=1$. Due to the rule $\chi_{m}+\chi_{a}=1$, one can use one from the master equations only to describe the transformation kinetics. Representing for example austenitic fraction as $\chi_{a}=1-\chi_{m}$ and substituting it into the first master equation, one can easily obtain the evolutionary kinetic equation for the fraction of martensitic phase:

$$
\dot{\chi}_{m}=-W^{m \rightarrow a} \chi_{m}+W^{a \rightarrow m} .
$$

Comparing this equation with Eq. (5) that found in framework of DEM, one could easily observe that these are similar each to other. Therefore, the corresponding kinetic coefficients following from the differential equation method as well as from the master equations must be equal too. That is, one can immediately find the following relations:

$$
\dot{T} \alpha_{ \pm}(T)=-W^{m \rightarrow a}-W^{a \rightarrow m}, \dot{T} \beta_{ \pm}(T)=W^{a \rightarrow m} .
$$

By using the results represented by Eq. (16), the evident expressions for the transition probabilities can be found as follows:

$$
\begin{aligned}
& W^{a \rightarrow m}= \pm \dot{T}\left(-\frac{d z_{ \pm}}{d T}\right)\left(\frac{z_{\mp}}{z_{+}-z_{-}}\right), \\
& W^{m \rightarrow a}= \pm \dot{T}\left(-\frac{d z_{ \pm}}{d T}\right)\left(\frac{1-z_{\mp}}{z_{+}-z_{-}}\right) .
\end{aligned}
$$

It is important that both $W^{m \rightarrow a}$ and $W^{a \rightarrow m}$ are always positively defined functions because all the terms included into the brackets are positive. It is especially important in order to their interpretation, as the transition probabilities were physically correct.

\section{CONCLUSIONS}

The most important conclusions following from the present study of 
the athermal type of MT-kinetics seem can be formulated as follows.

Each point inside the main loop represents one of the possible stationary two-phase states of the system. All these are the metastable ones, because no macroscopic changes are usually observed if one stops the cooling or heating process at any stage of transformation for any time. This also denotes that thermal fluctuations do not play any significant role in MT. As a result, transitions from one metastable state to another one are only possible on driving the system with any external thermodynamical force, such as a temperature or stress.

Successful description of the irreversible evolution of macroscopic variables caused by hysteresis is possible by using a special type of differential equations with the temperature dependent coefficient depending only on the main hysteresis loop shape. These equations make it possible to predict the macroscopic volume fraction evolution for an arbitrary temperature change process including the partial subloops. For this aim, one should know only the information about the temperature behaviour for transformation paths representing the main hysteresis loop.

Cory and McNichols in their original works have developed the phenomenological scheme of MT thermomechanics including as stress and temperature hysteresis effects as well as evident analytic expression of the partial transformation trajectories. Although these authors have not used any differential representation of their equations for partial transformation trajectories, nevertheless, one can easily reduce these equations to the same differential form that has been found in DEM. In particular, CM-approach can be considered as a small hysteresis limit of DEM.

To understand better the nature of differential equation method, a very important physical interpretation based on the master kinetic equation concept has been considered in this study. It is important that the earlier proposed DEM equations can be easily derived from this well known in physics general concept if only to apply it to the martensitic type transformation reactions: $a \leftrightarrow m$ (austenite $\leftrightarrow$ martensite).

By using the results found in framework of DEM, the evident expressions for the transition probabilities satisfying all the necessary physical conditions can be found as well.

\section{REFERENCES}

1. I. Cornelis and C. M. Wayman, Scr. Met., 10: 359 (1967).

2. K. Otsuka, C. M. Wayman, K. Nakai, H. Sakamoto, and K. Shimizu, Acta Met., 24: 207 (1979).

3. L. Delaey, J. Van Humbeeck, M. Chandrasekharan, J. Janssen, M. Andrade, and N. Mwamba, Metals Forum, 4: 164 (1981).

4. Yu. I. Paskal and L. A. Monasevich, Phys. Met. Metall., 52: 95 (1981). 
5. L. Lu, E. Aernoudt, and L. Deleay, Proc. of Eur. Symp. on Martensitic Transformation in Sci. and Tech., (March 9-19, 1989, Bochum, West Germany) (Ed. E. Hornbogen), p. 287.

6. J. S. Cory and J. L. McNichols, J. Appl. Phys., 58: 3282 (1985).

7. E. Aernoudt and L. Lu, Proc. of Int. Symp. 'Shape Memory Alloys' (Sept. 6-9, 1986 ) (Guilin: China Academic Publishers: 1986), p. 23.

8. L. Delaey and E. Aernoudt, Proc. of Int. Conf. 'Martensitic Transformations-ICOMAT-86', (Aug. 26-30, 1986) (Nara: The Japan Institute of Metals: 1987), p. 926.

9. I. D. Mayergoyz, J. Appl. Phys., 57: 3803 (1985).

10. P. Guelin and D. Favier, J. de Mechanique, 19: 217 (1980).

11. Yu. N. Koval and A. A. Likhachev, Metallofizika, 5: 28 (1988).

12. A. A. Likhachev and Yu. N. Koval, Scr. Met. et Mat., 27: 223 (1992).

13. J. Van Humbeeck and R. Stalmans, Mat. Sci. Forum, 56-58: 405 (1990).

14. J. Ortin, J. Appl. Phys., 71: 1454 (1992).

15. A. Visintin, Topics in Non-Smooth Mechanics (Eds. J. J. Moreau, P. D. Panagiotopulos, and G. Strang) (Basel: Birkhauser: 1988).

16. M. A. Krasnosel'skii and A. V. Pokrovskii, Systems with Hysteresis (Berlin: Springer: 1989).

17. Y. Ivshin and T. J. Pence, Int. J. Ing. Sci., 32: 681 (1994).

18. Y. Ivshin and T. J. Pence, Proc. of Int. Conf. 'on Martensitic Transformations-ICOMAT-92', (July 20-24, 1992) (Monterey Carmel, CA: Monterey Institute of Advanced Studies: 1993), p. 389.

19. J. Van Humbeeck, E. Aernoudt, L. Delaey, L. Lu, H. Verguts, and J. Ortin, Rev. Phys. Appl., 23: 557 (1988).

20. A. A. Likhachev and Yu. N. Koval, Fazovye Prevrashcheniya Martensitnogo Tipa [Martensitic-Type Phase Transformations], (Kiev: Naukova Dumka: 1993), p. 39-52 (in Russian).

21. A. A. Likhachev, Journal de Physique III, Colloque C2, 5: 465 (1995).

22. A. A. Likhachev, Scr. Met et Mat., 32: 663 (1995).

23. A. A. Likhachev and Yu. N. Koval, Metallofiz. Noveishie Technol., 18: 10 (1996).

24. A. Amengual, A. A. Likhachev, and E. Cesari. Scr. Met. et Mat., 34: 1549 (1996). 